\title{
Construction of College Personnel Files Management Informatization under the Background of Big Data
}

\author{
Yan Ma \\ Luohe Medical College, Luohe City, Henan Province, 462000, China
}

\begin{abstract}
Personnel files management is the fundamental work of human resources management in colleges, whose modernization and informatization construction should have a significant role in promoting human resources management in colleges. However, currently, the construction of personnel files informatization in colleges is only limited to personnel files digitalization and information electronization. Besides, only a simple sense of the personnel file information management system has been established, which cannot fundamentally solve the realistic difficulties in human resources management in colleges. In this paper, based on the authors' learning and practical experience, we firstly analyzed the necessity of the introduction of the big data technology into college files management, and then put forward the construction paths of college personnel files management informatization under the background of big data. Finally, the issues in application of big data in college files management were summarized. Key words: big data; college; personnel files; informatization management
\end{abstract}

\section{Introduction}

With the development of Internet technology and the extensive application of information technology, huge amount of data derived from the massive information of input and output among various roles have ushered in a new era of information explosion, namely big data era[1]. Big data, accompanied by the mature and rapid development of information technology such as cloud computation, mobile Internet and the Internet of Things, has set off a big data 
boom at home and abroad, and obtained wide attention in the industry and academia. The files industry has no exception. From a perspective of the big data, files departments should break the original mode of thinking, conduct the overall planning, and use the development vision to make the big data strategies in files departments.

\section{Necessity of the Introduction of Big Data Technology into College Files Management}

\subsection{Integration of archives into smart city needs the big data technology}

Archives, a scientific and cultural institution of permanently preserving and providing files for the society, has a mass of information resources, and is the focus of information resources. However, these information resources have not been effectively developed and utilized because of the backward management, lack of talents, and low awareness of social files. The construction of smart city is the real opportunity for the development and utilization of archival information resources, and a rare opportunity for archives to integrate into the city and improve its image. Smart city relies on the use of information. The true integration of the archives into the construction of smart city needs to revitalize the preserved massive information in every archives to integrate the information into the information flow of the smart city, which can be used by decisionmaking layer and the public[2]. It cannot be done only by the manpower, and must rely on the technology to revitalize the massive files information in various archives and dig out the valuable knowledge wealth. The big data processing technology is a good choice for solving the above issues.

\subsection{Massive electronic file management urgently needs the big data technology}

Big data applications mean large-scale data and huge number of files. Therefore, it is a problem to manage the metadata of layer accumulation in files system. Improper handling will affect the system's scalability and performance. Faced with of rapid growth of unstructured files, the archivists have many difficulties in the electronic files management. Currently, the database on the basis of big data technology such as SQL can do not only relational data, but also unstructured data such as spatial data, images and data flow. Moreover, the object-based storage architecture not only can manage billions of files in a single system, but also does not suffer from the same troubles in metadata management like the traditional storage. Big data technology provides a solution for the archivists to manage the problem of unstructured electronic files. 


\subsection{Massive files data storage and backup needs the big data technology}

The use of files database greatly improves the efficiency of files management and utilization. However, in recent years, the problem often encounters in the process of the use of the files database that the new files data cannot be added to the database. This phenomenon is very similar to "library expansion" in the traditional files management, namely the limited capacity of the library leads to problem that the added files cannot be properly stored to the library. While we sigh with regret for destruction of these official documents with huge files value, we are also alarmed at the size of the number of documents produced by the government. If these files is identified and archived, and files informationization is conducted, the amount of generated files is huge. With the gradual completion of files informationization and arrival of big data era, the problem of files database storage space is very serious[3].

\subsection{Files work from the entity management to knowledge management needs the big data technology}

Presently, archival users are not satisfied with the use of data or files. They hope to obtain the information behind the data and knowledge stored in the information. Therefore, archival services should also provide knowledge instead of data and information. The technology engine is the technical core of archival knowledge service. The new knowledge service engines include resource and academic search engine, resource and service recommendation engine, knowledge service community entity (including users and resources), behavioral intelligence analysis engine, user knowledge demand forecasting engine and multidimensional information resource acquisition, organization, analysis and decision-making engine. The use of big data technology can build up archives' new knowledge service engine.

\section{Construction Paths of Personnel Files Management Informatization in Colleges under the Background of Big Data}

\subsection{Change the concept of college files management leader}

The key to realize the successful application of big data management in personnel files management informatization in colleges is the leadership support and active participation of the department heads, especially the improvement in leadership thought awareness. Files management informatization and the use of big data are difficult to carry out in a department without a knowledge-based leadership in charge of the related work. Especially, the heads in charge of the modern college files management should be designated in college files management work[4]. 


\subsection{Strengthen the facilities construction of college files management}

Good software and hardware facilities are the basis for realizing the files management informationization. Advanced concepts without the facilities will not be realized. From the current situation, there are not any obstacles in technology and products aspects to achieve the integration of college information platform. The critical things are good hardware and software facilities. On the basis of reasonable accounting cost and input-output analysis, it is necessary to equip the facilities needed for archival management and to develop software that meets the requirements of big data management.

\subsection{The unified management of archival resources}

Big data technology supports the storage and processing of huge data, which makes the unified management and backup of archival resources possible. The big data industrial parks have been built up in some areas of China, which is enlightening on the files departments. The files need to be backed up in order to safeguard the safety of files and the comprehensive control of resources. Currently, the electronic backup is used in archives. Since there already have been data parks in China, and the important data departments have been settled, can the archives department in such big data industry parks establish a regional or national archives backup center? As long as rigorous verification and scientific planning are conducted, this measure is completely feasible. If the archival data resources in China can be concentrated, the use of big data technology for archival resources management, development and utilization will be just around the corner.

3.4 Seek for cooperation with big data development company, and develop analytical tools suitable for college files management

Data technology is wide and complex. If the big data is introduced into an industry, it is necessary to break the professional restrictions, and seek for cooperation with specialized big data development company, which can avoid the occurrence of the phenomenon that the company grasping the data analysis technology has no data, and the company not grasping the data analysis technology has plenty of data[5]. Different industries need different data analytical tools and development environment, which is also true for the college files management. Only by the cooperation between the archivists familiar with the files industry and professional companies or talents specialized for big data development, can the big data analytical tools suitable for the characteristics of college files management be developed.

\subsection{Pay attention to the security of big data application}

Big data management requires plenty of data storage. Once the data equipment and program fail, the accuracy of college files analysis will be directly affected. 
The safety and reliability of files storage have been related to the continuity of business in colleges. Once the system fails, the first test is the data storage, backup and recovery capabilities. If the data cannot be quickly restored, and the recovery cannot resume to the breakpoint, a direct damage can be constituted towards the college business and patient satisfaction. Security and reliability are the primary requirements for storage in the files management industry. The traditional data size is relatively small. Their backup and recovery is relatively easier, and the backup can be conducted in real time. At present, the clinical information system continuously increases, and becomes finer and finer. There may be dozens of systems. The number of servers is very large. Therefore, the consideration of security is very necessary[6].

\section{Issues in the Application of Big Data in College Files Management}

First, clear objectives and standards are needed. The use of big data in files management must clarify what can be got from the big data. Otherwise, it will take a lot of time to analyze the data. Archival resources are extremely rich. If there is no clear goals, even if one is not lost, he will feel very confused at least. Therefore, the goals and standards of the use of big data should be first defines, and then the big data tools can be used to solve specific problems. Second, the potential risks should be noticed[7]. The development and utilization of archival resources will involve in the issues including the archival information leakage, archival information loss and tampering, privacy violations and intellectual property disputes. Therefore, the potential risks should be noticed in the application of big data technology in the files management. The measures of formulating laws and regulations, clarifying permissions and responsibility can be adopted to control and deal with the occurrence of these potential risks.

\section{Conclusion}

The coming of the big data era is both an opportunity and a challenge to the college files management. The college archives need to seize this opportunity, and take the challenge seriously. With the development and perfection of the big data technology, the big data technology must have a broad application prospect. College files management will achieve a huge breakthrough in the era of big data. The huge knowledge treasure in the archival information resources will be able to truly developed and utilized. 


\section{References}

[1] JIANG Yachao. Study on files management work based on big data thinking. Lantai World, (08), pp.29-31, 2016.

[2] YU Yajuan. The impact of big data on the development of hospital files management. Files Management, (02), pp.85-86, 2016.

[3] CAI Lijian. Study on files management issues under the background of big data. Journal of Northwestern Polytechnic University (Later Social Science Edition), (01), pp.104-107, 2016.

[4] ZHANG Wenyuan, ZHANG Qian. BIg data technology and files data mining. Files Management, (02), pp.33-35, 2016.

[5] CUI Jie. Study on the challenges and opportunities in files management work under the background of big data.Technology, Culture and Education (Later February), (02), pp.187-188, 2016.

[6] CHEN Qi. Study on establishment of files big data application platform. Office Automation, (22), pp.39-41, 2015.

[7] LAN Zhugang, HUI Ying, LI Gang. The archival work in the big data era. China Achieves, (09), pp.74-75, 2013. 